\title{
E-Field Distribution in Ex-Vivo Porcine Skin Layer from a Subsurface UHF Transmitter
}

\author{
Noor Albadri ${ }^{1 *}$, Yana A. Salchak ${ }^{1}$, David V. Thiel ${ }^{1}$, Hugo G. Espinosa ${ }^{1}$ \\ ${ }^{1}$ School of Engineering and Built Environment, Griffith University, Brisbane, QLD 4111, Australia, \\ noor.al-badri@griffithuni.edu.au
}

\begin{abstract}
A tuned small slot antenna has been used for radio communications with internal transceivers/transmitters for invivo medical applications. The $2.45 \mathrm{GHz}$ properties (permittivity and conductivity) shows that porcine skin tissue can be used as a substitute for human skin tissue in medical applications. In this study, a measure of the E-field distribution on the skin surface of human and porcine tissue is presented. Ex vivo measurements on boneless layered pork belly-fat (45mm thick 300 $\mathrm{mm} \times 150 \mathrm{~mm}$ sample of skin, fat and muscle) were compared with numerical modelling for a subdermal PIFA tuned antenna. The surface electric field distribution is quite well matched to an analytical formula over a $70 \mathrm{~dB}$ dynamic range. The conductivity $\left(\sigma=4 \mathrm{~S} / \mathrm{m}, \varepsilon_{\mathrm{r}}=10\right)$ and relative permittivity adjusted to fit the measurement profile aligned with previously reported values. These results support the strategy that field strength measurements can be used to locate an injects radio transmitter.
\end{abstract}

Index Terms—skin layers, pork, ex-vivo, surface fields, lateral waves.

\section{INTRODUCTION}

Wearable antennas have many applications in the medical industry as body sensor networks. Since the antenna operates in close proximity or is directly attached to the human body, compact design is important for patient comfort and ease of use particularly if the unit must be worn for longer time periods [1-4]. Other common requirements include low profile, lightweight, mechanical flexibility, easy fabrication, and low cost $[5,6]$.

When an object lies in the near field of an antenna, it becomes part of the radiating structure. If the material is lossy, then the antenna efficiency is reduced. If the object is large, then the radiation pattern has an increased number of side-lobes. These effects are not well understood, particularly as the human torso is multilayered with skin, fat, muscle and organs having different electromagnetic properties. In addition, these biomedical structures are different for every human.

While animals have similar biological properties to humans, in medical research, animals are widely used in the development of new medical technologies [7-9]. Antennas on skin are affected (gain, impedance, etc) by the dielectric properties of the skin. Several measurements of the dielectric properties of porcine skin have reported similarities to human skin [10-12].

\section{EPIDERMAL AND SUBDERMAL ANTENNA MEASUREMENTS}

The design process for intra/inter body communications application must include matching the antenna to the electrical properties and the approximate structure of the skin, fat and muscle near the skin surface. These applications normally have the antenna in direct contact with the skin surface or inserted in the tissue layers to resonate at Industrial, Scientific and Medical (ISM) band frequencies (commonly $433 \mathrm{MHz}$ or $2.45 \mathrm{GHz}$ ). These electrical properties vary with the location on the skin surface and between individuals. While a simple monopole on the skin surface is affected by the inward (tissue) and temporal outward materials (including air, clothing, other body parts). A slot antenna [6] is less influenced by external changes however is more strongly influenced by the immediate subsurface tissue layers. Two different antenna configurations were used in this study. Both were modelled in Computer Simulation Technology CST studio ${ }^{\circledR}$ and fabricated. The slot antenna was tested on both the torso of a living human and a pork skin/fat/muscle sample, whereas the PIFA (planar inverted F antenna) [13] was used as an implied internal transmitter beneath the pork sample. Both antennas were adjusted to ensure adequate self-resonance at $2.45 \mathrm{GHz}$ using the software before construction.

\section{A. Inward-looking antenna design as receiver:}

The inward-looking slot antenna was presented in [6], was reconfigured to resonate at $2.45 \mathrm{GHz}(-24 \mathrm{~dB})$ when pressed against the soft tissue of the human torso in-vivo. The antenna box was machined from an aluminium block and consists of an aluminium box with a resonant slot internally coupled with a monopole probe and coaxial cable (see Fig. 1). The path loss from an internal radio transmitter can be measured principally as a line-of-sight path, but with surface propagation also a possibility. If the material has relatively low loss, an interference pattern can be observed between the surface propagation mode and the line-of-sight direct radiation - an effect known as lateral wave propagation $[14,15]$. In addition, the lower impedance fat tissue may act as a guiding layered structure. This depends on the fat layer depth of each person and different anatomical positions [16]. In all cases the places where the bone was close to the antennas was avoided. For simplicity and to a good approximation the tissue can be considered uniform 
and the surface fields on the torso can be calculated for all ingested radio pill position in the gut [17].

The radiation pattern of slot antenna measured in the air shows a relatively uniform radiation pattern in the forward direction. Fig. 2 shows the E-plane and H-plane radiation characteristics. SAR modelling for this type of antenna has been previously reported [6]. It is anticipated that this radiation pattern is substantially altered when placed against the human torso.
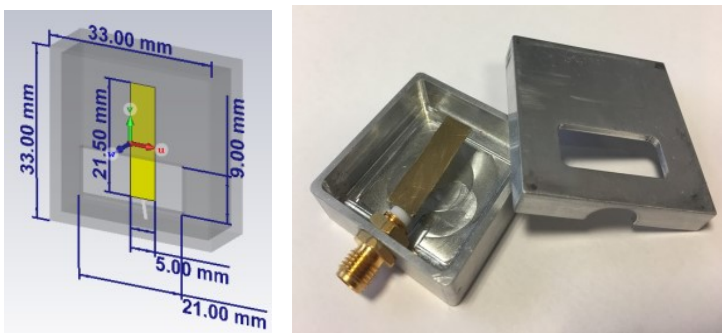

Fig. 1. The slot antenna consisted of a machined aluminium box with a monopole feed. The antenna was optimised in software to resonate at $2.45 \mathrm{GHz}$ when placed on the human torso.

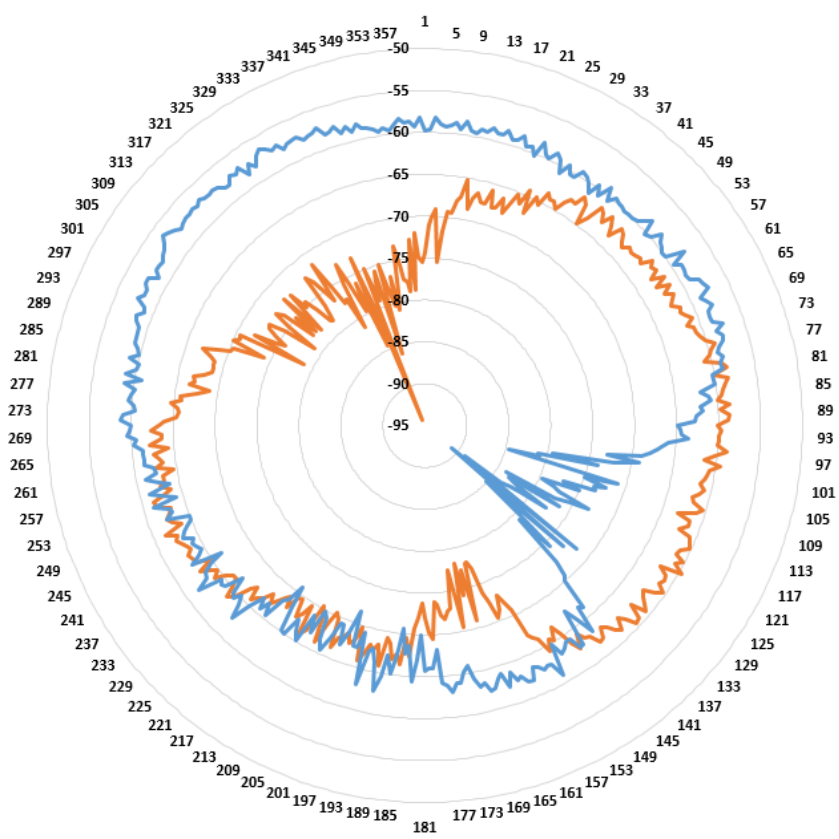

Fig. 2. Slot antenna radiation pattern in the $\mathrm{E}$ and $\mathrm{H}$ plane measured in air at $2.45 \mathrm{GHz}$.
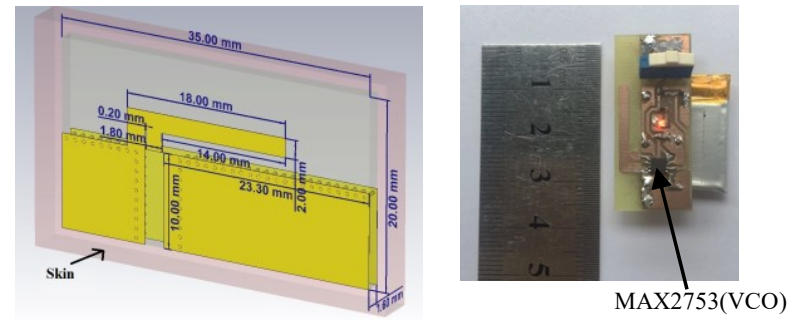

Fig. 3. The PIFA antenna was modified to resonate at $2.45 \mathrm{GHz}$ when surrounded by human tissue. Right: The complete circuit with generator and PIFA antenna with the small lithium-ion battery beneath.

\section{B. Planar Inverted F antenna PIFA as a transmitter:}

The conventional PIFA on FR4 was optimized using CST to resonate across the frequency band $2.1-2.5 \mathrm{GHz}$. At 2.45 $\mathrm{GHz}$ when surrounded by human tissue, the return loss $\mathrm{S}_{11}=$ $13.3 \mathrm{~dB}$. The dielectric substrate $\left(\varepsilon_{\mathrm{r}}=4.4\right)$, measured $35 \mathrm{~mm}$ x $20 \mathrm{~mm}$ with thickness $1.6 \mathrm{~mm}$ (see Fig. 3 ). The 2-layered printed circuit board also included the UHF generator electronics and battery connections.

The complete circuit (PIFA + generating electronics) included a voltage controlled oscillator (VCO) (MAX2753, Maxim Integrated Products, Inc., Sunnyvale, CA, USA) and a lithium-ion battery under transmitter electronics PCB.

\section{EXPERIMENTAL RESULTS}

\section{A. Layered epidermal and subdermal tests:}

The fresh porcine skin layers extracted from the pig abdomen belly were provided from a local butcher with all bones removed. The rectangular sample measured $300 \mathrm{~mm} x$ $150 \mathrm{~mm} \times 45 \mathrm{~mm}$. It was provided, measured and disposed on the same day of the experiment. The skin was hairless (shaved) and maintained at room temperature $24{ }^{\circ} \mathrm{C}$ in the laboratory. As both human and porcine skin tissues have close relative permittivity and conductivity [11]. The skin thickness of the pork was $2 \mathrm{~mm}$, the fat layer average thickness was approximately $15 \mathrm{~mm}$ and the other was a combination of muscle and fat was $28 \mathrm{~mm}$ (see Fig. 4).

In this study, the E-field distribution on the skin surface of the porcine tissue was investigated using Vector network analyzer (VNA) to measure $\mathrm{S}_{21}$. Two identical slot antennas were used. One antenna was placed centrally under the sample directly against the muscle and the other was moved systematically along the skin surface (Fig. 5).

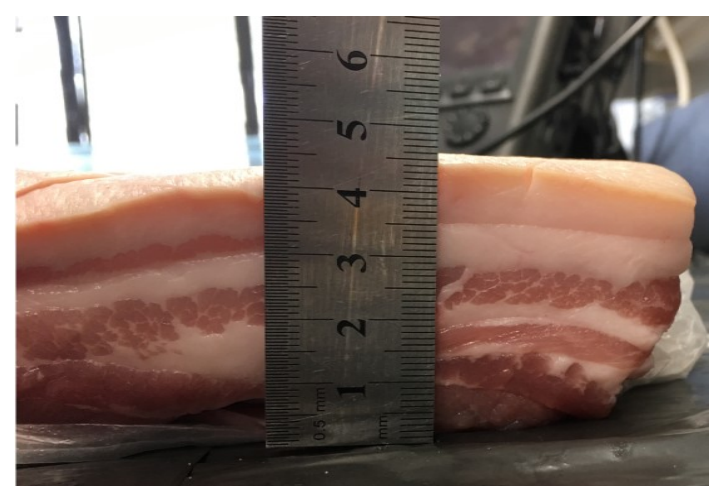

Fig. 4. Pork belly fat cross-section showing the muscle (bottom layer), various fat and muscle layers, with a thicker fat layer between the skin (top layer). The overall thickness was approximately $45 \mathrm{~mm}$.

Measurements were taken at both epidermal and subdermal locations of the porcine multilayer tissue stepwise $(25 \mathrm{~mm})$ across the length of the sample.

A small, battery-powered spectrum analyzer (RF Explorer) was used to observe the received signal strength from the PIFA transmitter every $25 \mathrm{~mm}$. The transmitter (PIFA circuit) was located at $125 \mathrm{~mm}$ from the end of the 
sample for most measurements distance from Edge1 (Fig. 5), and $75 \mathrm{~mm}$ from Edge 3. The PIFA antenna was also inserted inside the tissue layers at a distance of $75 \mathrm{~mm}$ from Edge 4 and was fully surrounded by the fat layer (Fig. 6). Table I shows the various locations of the $\mathrm{Rx}$ and $\mathrm{Tx}$ antennas on/in the porcine tissue.

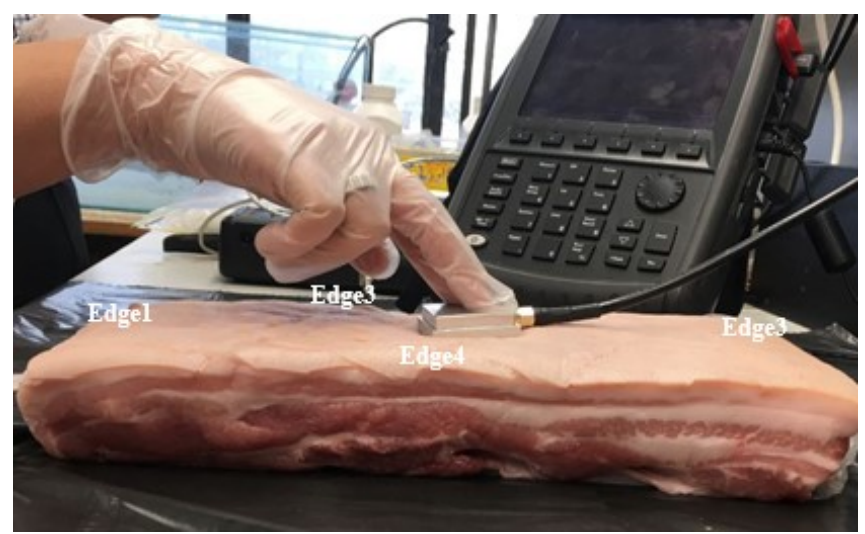

Fig. 5. $\mathrm{S}_{21}$ measurements using a slot antenna positioned across the skin surface. The second antenna is located underneath the pork sample.

TABLE I: TRANSMITTER AND RECEIVER LOCATIONS USED IN THE PORK MEASUREMENTS. THE CENTRE DISTANCE FROM EDGE 1 IS $125 \mathrm{MM}$

\begin{tabular}{|c|c|c|c|c|}
\hline $\mathbf{R x}$ & $\mathbf{T x}$ & $\begin{array}{c}\text { Tx depth } \\
\text { from skin } \\
\text { surface(m } \\
\text { m) }\end{array}$ & $\begin{array}{c}\text { Tx } \\
\text { distance } \\
\text { from the } \\
\text { Edge1 }(\mathbf{m m})\end{array}$ & $\begin{array}{c}\text { Tx } \\
\text { distance } \\
\text { from the } \\
\text { Edge4 } \\
(\mathrm{mm})\end{array}$ \\
\hline \multirow{6}{*}{$\begin{array}{l}\text { Inward- } \\
\text { looking } \\
\text { antenna }\end{array}$} & $\begin{array}{c}\text { Inward- } \\
\text { looking } \\
\text { antenna } \\
\text { (Experiment) }\end{array}$ & 45 & 125 & \multirow{6}{*}{75} \\
\hline & $\begin{array}{c}\text { Inward- } \\
\text { looking } \\
\text { antenna } \\
(\mathrm{CST}) \\
\end{array}$ & 45 & 125 & \\
\hline & PIFA & 45 & 125 & \\
\hline & PIFA (CST) & 45 & 125 & \\
\hline & PIFA & 35 & 255 & \\
\hline & PIFA & 25 & 125 & \\
\hline
\end{tabular}

\section{B. Numerical Modelling (pork and human):}

The porcine sample layers were modelled in CST with the electromagnetic properties of a porcine tissue at $2.45 \mathrm{GHz}$. The thickness of the layers (skin, fat and muscle) were same as the real sample and was scaled on the skin surface from Edge $1=0 \mathrm{~mm}$ distance to Edge2=300 $\mathrm{mm}$ (Fig. 7). The transmission $\left(\mathrm{S}_{21}\right)$ for the Rx was tested at each 25 $\mathrm{mm}$ when the slot antenna was the transmitter at $45 \mathrm{~mm}$ from the skin surface. Similarly, $\mathrm{S}_{21}$ for the PIFA antenna (Tx) and $\mathrm{S}_{12}$ for the Rx (Fig. 7).

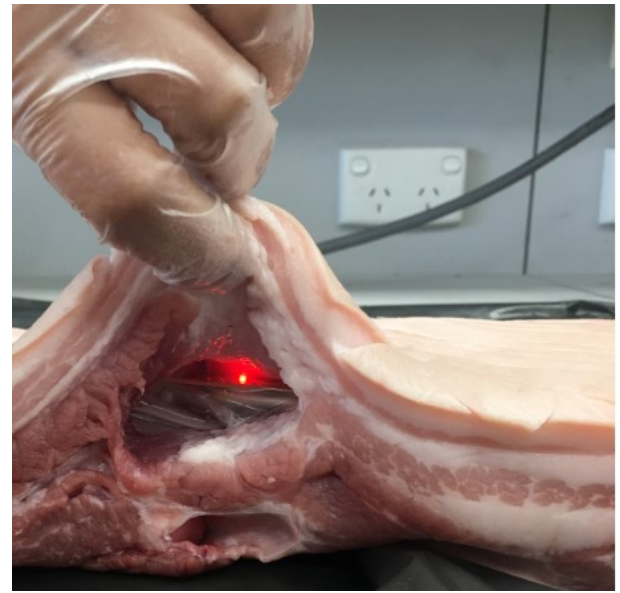

Fig. 6. The PIFA transmitter (red light) was located between the tissue layers for some measurements. The air gap was removed before the measurements were undertaken.
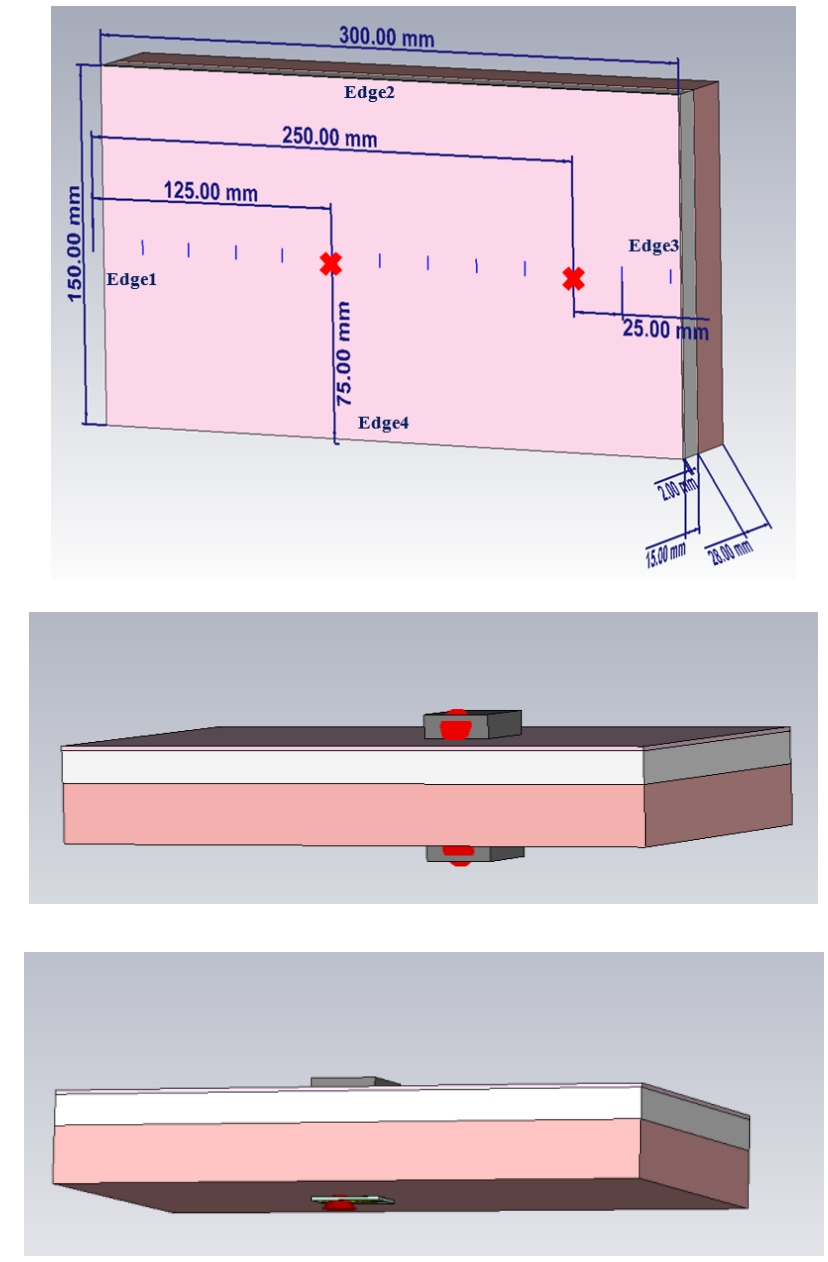

Fig. 7. The CST model of the porcine tissue sample. Top: dimensions of the sample; centre: the S21 measurements using two slot antennas, bottom: the PIFA antenna on the bottom of the sample. 


\section{RESULTS}

\section{A. Experimental Results}

The normalised field strength data from the PIFA and the $\mathrm{S}_{21}$ data measured and modelled is given in Fig. 8. There are two features of significant interest:

- The width of the peaks is quite different for all of the measurement and modelled techniques, and

- There are indications of small lateral field strength maxima which resemble the previous observations of lateral waves.

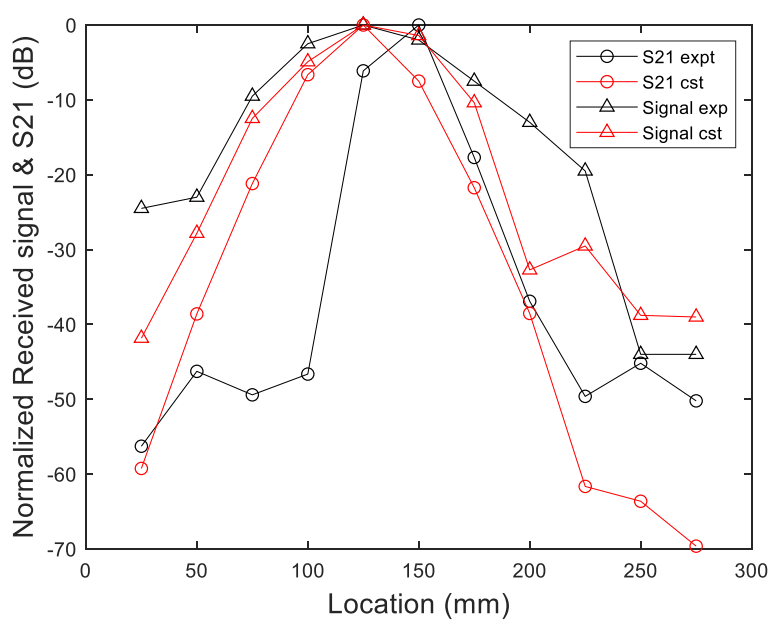

Fig. 8. The CST and experimental measurements of the surface field on the porcine tissue sample with the PIFA antenna located at distance $125 \mathrm{~m}$.

These two observations were explored further by more closely spaced CST modelling of the surface field without the inclusion of the slot antenna as a detector. Fig. 9 shows the results of these investigations. The equivalent human tissue values were also included for comparison. The variations of the field strength due to the lateral wave although the locations are slightly different due to the difference in the electromagnetic parameters (conductivity and relative permittivity). Another significant feature is the field intensity minimum immediately above the transmitter. This was also observed in the sand hill lateral wave measurements [15]. This was not observed experimentally because the aperture of the slot antenna is quite large in comparison with the single point minimum value. As the width of the field intensity peaks is particularly important in location calculations [17] the forward model showed a matching beam width when $\sigma=4 \mathrm{~S} / \mathrm{m}$ and $\varepsilon_{r}=10$. This simple model does not include the lateral wave effects some distance away from the transmitter.

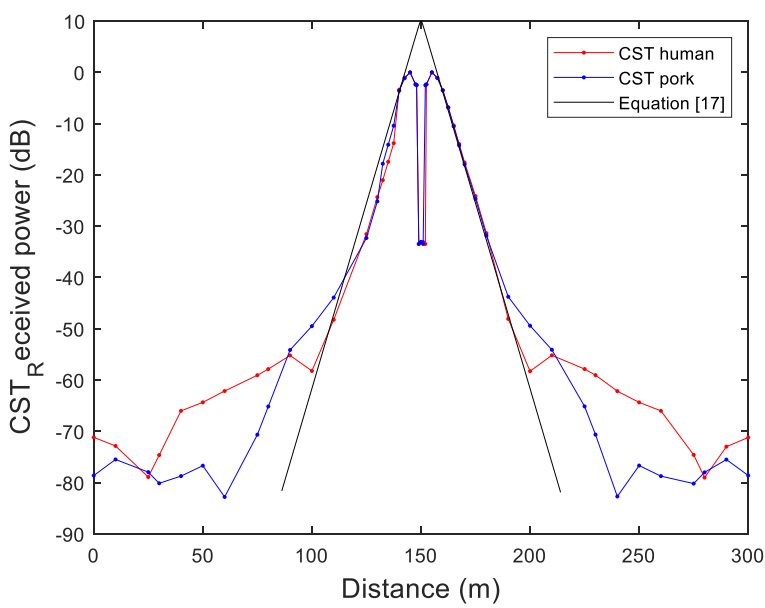

Fig. 9. CST modelling of the $2.45 \mathrm{GHz}$ surface field on the porcine tissue sample with the PIFA antenna located at distance $150 \mathrm{~mm}$. The equivalent human tissue parameters for the same configuration is also plotted. The fitted analytical solution from [17] was used to estimate the electromagnetic parameters of the pork.

A further computational study was undertaken to match the peak width of these modelled results with the experimental measurements. These results are given in Fig. 10. This calculation only included the direct radiation field and not the lateral wave. The experimental data was matched to this simplified model defined in [17] by varying the conductivity and relative permittivity of the tissue. Similar results were obtained when the transmitter was placed between the tissue layers for surface field measurements.

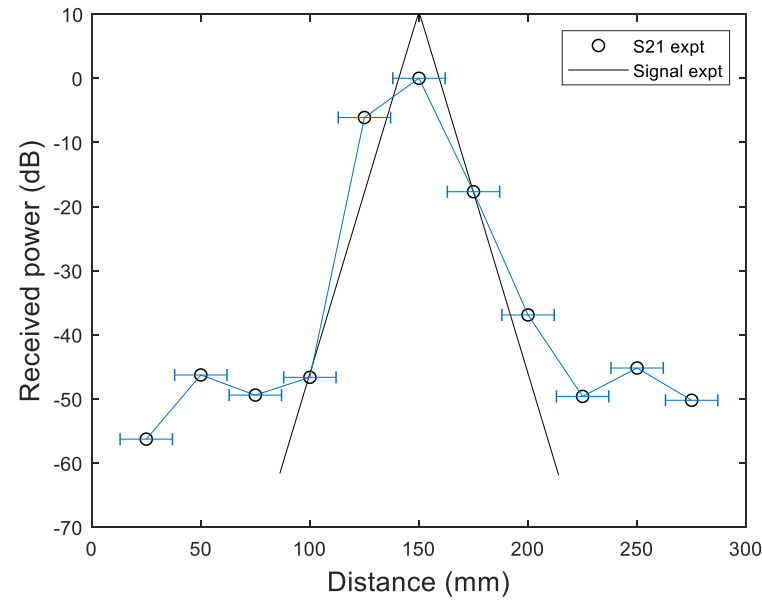

Fig. 10. A comparison of a line-of-sight attenuation model [17] with the experimental results for transmission through the pork sample. The conductivity $(\sigma=2.8 \mathrm{~S} / \mathrm{m})$ and relative permittivity $\left(\varepsilon_{r}=10\right)$ have been adjusted to improve the match. The measurement positions have an uncertainty of $\pm 6 \mathrm{~mm}$. 


\section{CONCLUSION}

The complex structure and the finite dimensions of the porcine sample cannot be perfectly matched in the CST model. The muscle tissue is anisotropic and the sample contains different fat types which will have different electrical properties. The pork tissue was fresh but had been drained of blood and other fluids. This will impact on the electromagnetic properties of the sample. This means that the modelled parameters are possibly different from the measurements. Despite these uncertainties this research has demonstrated that:

- $\quad$ The porcine and human tissue electrical parameters are similar and so pork studies can be used as a human analog.

- The uniform analytical model [17] provides an adequate match over a $70 \mathrm{~dB}$ dynamic measurement range.

- The slot antenna has a relatively uniform radiation pattern and has provided a robust method of measuring the surface electric field distribution from an internal transmitter.

- There is a significant probability that the electromagnetic properties of humans in vivo lie in the impedance range where lateral wave affects can occur at very low signal levels. This can impact on the use of the simple algorithm for radio pill location.

These challenges will be addressed in further work planned using in-vivo animal experiments.

\section{ACKNOWLEDGMENT}

N.A. would like to thank Griffith University for her Student Postgraduate Scholarship.

\section{REFERENCES}

[1] A. Arif, M. Zubair, M. Ali, M. U. Khan, and M. Q. Mehmood, "A compact, low-profile fractal antenna for wearable on-body WBAN applications," IEEE Antennas and Wireless Propagation Letters, vol. 18, no. 5, pp. 981-985, 2019.

[2] M. Mustaqim, B. A. Khawaja, H. T. Chattha, K. Shafique, M. J. Zafar, and M. Jamil, "Ultra-wideband antenna for wearable Internet of Things devices and wireless body area network applications," International Journal of Numerical Modelling: Electronic Networks, Devices and Fields, p. e2590, 2019.

[3] M. S. Miah, A. N. Khan, C. Icheln, K. Haneda, and K. Takizawa, "Antenna system design for improved wireless capsule endoscope links at $433 \mathrm{MHz}$," IEEE Transactions on Antennas and Propagation, vol. 67, no. 4, pp. 2687-2699, 2019.

[4] Y. Liu, A. Levitt, C. Kara, C. Sahin, G. Dion, and K. R. Dandekar, "An improved design of wearable strain sensor based on knitted RFID technology," IEEE Conference on Antenna Measurements \& Applications (CAMA), pp. 1-4, 2016.

[5] S. Agneessens, S. Lemey, T. Vervust, and H. Rogier, "Wearable, small, and robust: The circular quarter-mode textile antenna." IEEE Antennas and Wireless Propagation Letters, vol. 14, pp. 1482-1485, 2015.

[6] M. Fernandez, D.V. Thiel, A. Arrinda and H.G. Espinosa, "An inward directed antenna for gastro-intestinal radio pill tracking at 2.45 GHz", Microwave \& Optical Tech. Lett., vol 60 (7), pp. 1644-
$1649,2017$.

[7] M. Lazebnik, M. C. Converse, J. H. Booske, and S. C. Hagness, "Ultrawideband temperature-dependent dielectric properties of animal liver tissue in the microwave frequency range," Physics in Medicine \& Biology, vol. 51, no. 7, p. 1941, 2006.

[8] T. Karacolak, R. Cooper, and E. Topsakal, "Electrical Properties of Rat Skin and Design of Implantable Antennas for Medical Wireless Telemetry," IEEE Transactions on Antennas and Propagation, vol. 57, no. 9, pp. 2806-2812, 2009.

[9] K. O. Olawale, R. J. Petrell, D. G. Michelson, and A. W. Trites, "The dielectric properties of the cranial skin of five young captive steller sea lions (Eumetopias jubatus), and a similar number of young domestic pigs (Sus scrofa) and sheep (Ovis aries) between 0.1 and $10 \mathrm{GHz}$," Physiol. Meas., vol. 26, pp. 627-637, 2005.

[10] E. S. Nadimi et al., "In vivo and in situ measurement and modelling of intra-body effective complex permittivity," Healthcare Technology Letters, vol. 2, no. 6, pp. 135-140, 2015.

[11] M. Vallejo, J. Recas Piorno, P. Valle, and J. Ayala, "Accurate human tissue characterization for energy-efficient wireless on-body communications," Sensors, vol. 13, pp. 7546-69, 06/01, 2013.

[12] R. A. Kleismit, G. Kozlowski, B. D. Foy, B. E. Hull, and M. Kazimierczuk, "Local complex permittivity measurements of porcine skin tissue in the frequency range from $1 \mathrm{GHz}$ to $15 \mathrm{GHz}$ by evanescent microscopy," Phys. Med. Biol., vol. 54, pp. 699-713, 2009.

[13] T. Pattnayak and G. Thanikachalam, "Antenna design and RF layout guidelines", Cypress Press AN91445. Online http://cypress.com/go/AN91445 accesed September 2019.

[14] R. W. P. King and M. F. Brown, "Lateral electromagnetic waves along plane boundaries: A summarizing approach," Proc. IEEE, vol. 72, no. 5, pp. 595-611, May 1984

[15] A. Emelyanenko, S.G. O'Keefe, H.G. Espinosa and D.V. Thiel, "Surface field measurements from a buried UHF transmitter: Theory, modeling and experimental results", IEEE Trans. Antennas and Propag., vol 65 (8), pp. 4389-4393, 2017.

[16] N. Albadri, H.G. Espinosa, J. Hides and D.V. Thiel, "The effect of human tissue on field strength measurements in vivo using a resonant UHF slot antenna", unpublished. 2019

[17] Y.A. Salchak, H.G. Espinosa and D.V. Thiel, "Modelling the surface field from an ingested radio transmitter with an approximate attenuation model for gastroenterology investigations", IEEE Trans. Biomedical Engineering, (in press), 2019. 